\title{
Pelatihan dan Pendampingan Pencatatan Pembukuan Keuangan dan Pembuatan Website Bengkel Waras Motor Denpasar
}

\author{
${ }^{1}$ Agus Purwanto, ${ }^{2}$ M. Azman Maricar, ${ }^{3}$ Ni Kadek Sukerti, ${ }^{4}$ Anggun Nugroho \\ ITB STIKOM Bali ${ }^{1}$, ITB STIKOM Bali ${ }^{2}$, ITB STIKOM Bali ${ }^{3}$, ITB STIKOM Bali ${ }^{4}$ \\ *Email: agusp712@stikom-bali.ac.id, azman@stikom-bali.ac.id, dektisamuh@gmail.com, anggun@stikom- \\ bali.ac.id
}

\begin{abstract}
ABSTRAK
Bengkel Waras Motor yang berkedudukan di jalan Tukad Buaji No. 1A, Denpasar Selatan merupakan usaha yang berawal dari usaha keluarga. Selama ini pencatatan pembukuan keuangan masih dilakukan secara manual dengan membuat catatan transaksi keuangan masuk dan keluar di buku pembukuan. Demikian juga mengenai pengelolaan penjadwalan job masih dilakukan dengan cara konvensional sehingga apabila terkendala masalah ketersediaan sparepart akan menjadi kendala. Meskipun demikian bengkel ini memiliki pelanggan setia dan jumlah omset pendapatan yang cukup baik dari tahun ke tahun karena mayoritas pelanggan adalah kenalan dan kualitas pekerjaan yang baik. Tujuan dari kegiatan pengabdian ini adalah meningkatkan kualitas pelayanan dan menguatkan pengelolaan keuangan dan sparepart yang lebih baik dan pemasaran melalui website. Metode pelaksanaan pengabdian berupa pelatihan dan workshop tentang pencatatan pembukuan keuangan yang lebih baik dengan menggunakan Microsoft Excel dan memenuhi standar akuntansi sederhana. Pembuatan website perusahaan digunakan untuk sosialisasi profil company dan media pemasaran yang memanfaatkan teknologi internet. Hasil pelaksanaan kegiatan ini mitra dapat melakukan pencatatan pembukuan keuangan menggunakan Microsoft Excel dan melakukan pengelolaan website sebagai media informasi dan meraih segmen pelanggan baru.
\end{abstract}

Kata kunci : pelatihan, pembukuan keuangan, pemasaran, website.

\section{ABSTRACT}

Waras Motor Workshop located at Jalan Tukad Buaji No. 1A, South Denpasar is a business that started as a family business. So far, financial accounting records are still done manually by recording incoming and outgoing financial transactions in the bookkeeping. Likewise, the management of jobs scheduling use conventionally way so that if it is constrained the problem of spare parts availability will be an obstacle. Even so, this workshop has loyal customers and a good income turnover from year to year because the majority of customers are acquaintances and the high quality of works. The purpose of this service activity is to improve service quality and strengthen financial management and better spare parts and marketing through the website. The method of implementing community service is in the form of training and workshops on better financial accounting records by using Microsoft Excel and meeting simple accounting standards. Creating a company website is used to socialize company profiles and marketing media that utilize internet technology. From the implementation of this activity, the partner can record financial bookkeeping using Microsoft Excel and manage the website as a medium of information and reach new customer segments.

Key words: training, accountant note, marketing, website 


\section{PENDAHULUAN}

Perbaikan dan pemeliharaan terhadap kendaraan bermotor sangat diperlukan oleh setiap penggunanya. Selain bengkelbengkel resmi dari masing-masing dealer kendaraan, terdapat banyak bengkel yang merupakan jenis usaha yang dibuat oleh masyarakat pada umumnya. Bengkel merupakan tempat dimana pengguna kendaraan transportasi, khususnya mobil, dapat melakukan perbaikan dan pemeliharaan kendaraannya yang dibantu oleh teknisi-teknisi di bidangnya. Setiap bengkel tentunya perlu melakukan transaksi pembelian sparepart, alat-alat yang dibutuhkan untuk perbaikan dan pemeliharaan kendaraan, serta hal-hal lain yang dibutuhkan. Selain melakukan pembelian, setiap bengkel juga melakukan transaksi penjualan terhadap pelanggannya, baik itu penjualan sparepart yang digunakan maupun penjualan jasa perbaikan dan pemeliharaan kendaraan.

Bengkel Waras Motor merupakan sebuah usaha yang dikelola oleh Bapak Waras yang memberikan pelayanan berupa perbaikan dan pemeliharaan (perawatan) mobil dari berbagai merek mobil. Usaha tersebut telah digeluti selama 20 tahun dan beralamat di Jalan Tukad Buaji No. 1A, Denpasar Selatan, Kota Denpasar. Karyawan yang ada pada Bengkel Waras Motor ini berjumlah 3 orang dengan berbagai kemampuan di bidangnya masing-masing. Selain karyawan bagian mekanik/montir, putra pemilik bengkel yang mempunyai pendidikan cukup juga membantu di bagian pembukuan dan sparepart, sehingga dapat dilatih untuk mengelola pencatatan keuangan secara komputerisasi dan mengelola website yang akan dibuat nantinya.

Usaha ini masih menggunakan cara manual untuk pencatatan pembukuan keuangannya, baik itu untuk kas masuk maupun kas keluar. Sehingga pemilik merasakan kesulitan untuk dalam menghitung omset, laba kotor serta pendapatan bersih usaha. Selain itu dari segi pemasaran, usaha ini masih menggunakan cara-cara konvensional, sehingga pendapatan kotor dari jasa perbaikan berkisar 10 juta rupiah dari sekitar 100 pelanggan yang dilayani per bulannya atau rata-rata 4 pelanggan per harinya. Pengeluaran rutin yang dibayarkan meliputi gaji tenaga kerja sebesar 5 juta rupiah dan biaya listri dan air serta voucher HP sebesar 1.5 juta rupiah, belum lagi biaya penyusutan peralatan sehingga laba bersih berkisar 3 juta rupiah. Pada pengabdian ini difokuskan untuk memberikan pelatihan dan workshop pencatatan pembukuan keuangan dengan menggunakan tool dari hasil teknologi informasi yang ada, selain itu akan dibuatkan sebuah website yang dapat digunakan untuk melakukan pemasaran terkait usaha tersebut. Dengan diadakannya pengabdian masyarakat ini diharapkan akan meningkatkan omset menjadi 15 juta rupiah per bulan yang akan menaikkan pendapatan bersih menjadi 4.5 juta rupiah per bulan.

Target luaran yang ingin dicapai melalui kegiatan ini adalah menghasilkan pemahaman mengenai pencatatan pembukuan keuangan (kas masuk dan kas keluar) dengan teknologi informasi agar lebih memudahkan dalam kegiatan tersebut dan juga menghasilkan sebuat website yang dapat digunakan sebagai media pemasaran terkait usaha. Untuk mencapai luaran tersebut, maka dilakukan dengan cara melakukan pelatihan dan workshop terkait pencatatan pembukuan keuangan (kas masuk dan kas keluar) dengan menggunakan teknologi yang ada serta pembuatan website guna menunjang pemasaran usaha sehingga pada akhirnya akan mampu mempermudah pembukuan keuangan serta meningkatkan jumlah pelanggan pada Bengkel Waras Motor.

Gambaran analisis situasi mitra sebelum dilaksanakan kegiatan pengabdian dapat dilihat pada tabel 1 . 
Tabel 1. Analisis Situasi

\begin{tabular}{|l|l|l|l|}
\hline No & Bidang & Permasalahan & Solusi \\
\hline 1 & $\begin{array}{l}\text { Pencatatan } \\
\text { pembukuan } \\
\text { keuangan }\end{array}$ & $\begin{array}{l}\text { Pencatatan } \\
\text { secara manual } \\
\text { dan belum } \\
\text { memenuhi } \\
\text { standar } \\
\text { akuntansi }\end{array}$ & $\begin{array}{l}\text { Diberikan } \\
\text { pelatihan } \\
\text { pencatatan } \\
\text { pembukuan } \\
\text { keuangan } \\
\text { memanfaatkan } \\
\text { PC }\end{array}$ \\
\hline 2 & Pemasaran & $\begin{array}{l}\text { Pemasaran } \\
\text { secara } \\
\text { konvensional }\end{array}$ & $\begin{array}{l}\text { Pelatihan } \\
\text { pemasaran } \\
\text { melalui internet }\end{array}$ \\
\hline
\end{tabular}

\section{RUMUSAN MASALAH}

Adapun permasalahan yang dari analisis situasi yang dilakukan pada Bengkel Waras Motor adalah sebagai berikut :

a. Mitra belum menggunakan teknologi informasi dalam melakukan pencatatan pembukuan keuangan dan mengalami masalah dalam menghitung omset, laba kotor serta pendapatan bersih.

b. Mitra belum melakukan pemasaran secara maksimal yang dapat lebih meningkatkan omset dan jumlah pelanggan. Dibutuhkan website sebagai media pengenalan dan pemasaran jasa bengkel.

\section{METODE}

Berdasarkan permasalahan yang dihadapi mitra, maka dalam usulan pengabdian masyarakat ini, solusi yang dapat ditawarkan yaitu:

1. Pelatihan pencatatan pembukuan keuangan memanfaatkan PC dan software Microsoft Excel.

2. Perancangan dan pembuatan website untuk keperluan penyampaian informasi sekaligus sebagai media pemasaran.

3. Pelatihan, pendampingan pengelolaan back office side agar pengelola bengkel dapat mengelola dengan lancar dalam penyampaian informasi dan pemasaran melalui website.

Tahapan tersebut dapat digambarkan seperti bagan pada gambar 1 , berikut ini.

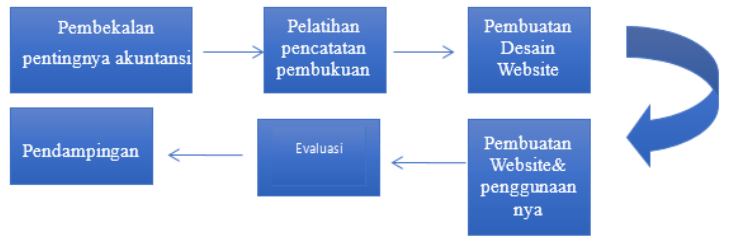

Gambar 1. Tahapan pengabdian

Peserta kegiatan pelatihan ini adalah staff dan pengelola bengkel WARAS Motor.

\section{PEMBAHASAN KEGIATAN}

Kegiatan pengabdian masyarakat yang telah dilakukan pada bengkel mobil WARAS Motor, yaitu berupa :

1.Pembekalan tentang pentingnya pencatatan keuangan yang baik.;

2. Pelatihan pencatatan transaksi keuangan dengan standar akuntansi menggunakan software Microsoft Excel.

Materi Pelatihan :

a. Pencatatan Jurnal Akuntansi

b. Pembuatan Buku Besar

c. Pembuatan Laporan Laba - Rugi

d. Pembuatan Laporan Neraca Saldo

3. Pelatihan pengelolaan website untuk membagi informasi dan mendorong pemasaran.

Materi Pelatihan :

a. Langkah pembuatan website.

b. Pelatihan tata cara pemanfaatan PC yang ada untuk terhubung dengan jaringan internet.

c. Pengelolaan back side dari website perusahaan.

d. Pengelolaan pemasaran melalui website.

Berikut ini gambaran kegiatan yang disertai dengan foto - foto kegiatan:

\section{Bengkel Mobil WARAS MOTOR}

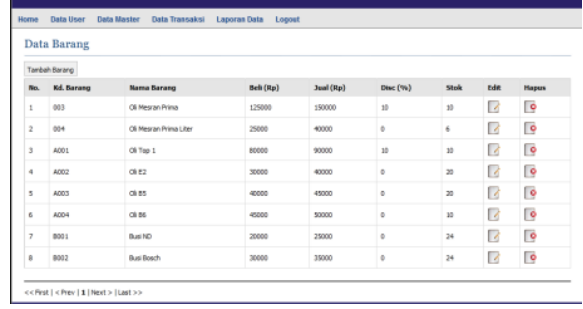

Gambar 2. Pencatatan Data Barang 


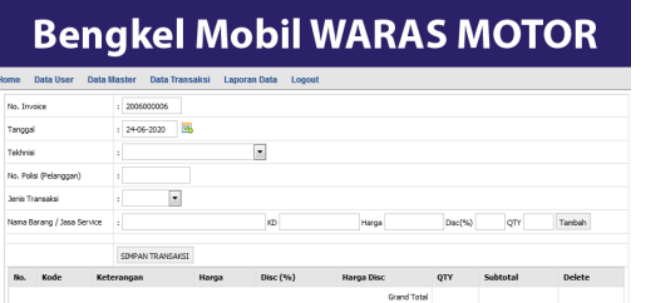

Gambar 3. Pencatatan Data Transaksi
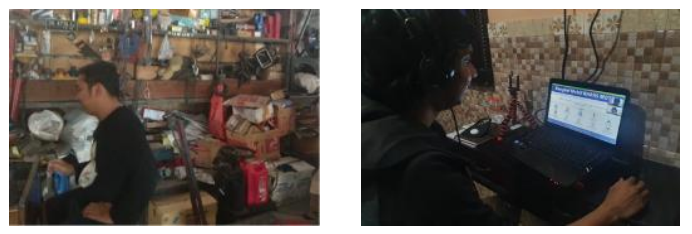

Gambar 4. Pelatihan pencatatan keuangan

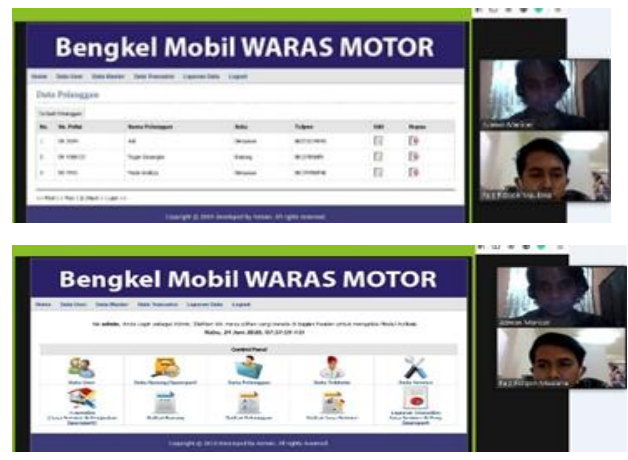

Gambar 5. Pelatihan pengelolaan website secara daring

\section{Prosedur Kerja}

Prosedur kerja dan rencana kegiatan yang dilaksanakan dalam pengabdian masyarakat ini adalah sebagai berikut:

1. Pembekalan pentingnya pencatatan keuangan yang baik

2. Pelatihan pencatatan transaksi keuangan dengan standar akuntansi

3. Pembuatan Desain Website

4. PembuatanWebsite dan pelatihan penggunaannya

5. Evaluasi Kegiatan Pelatihan

6. Pendampingan

\section{Partisipasi Mitra}

Kegiatan pengabdian ini merupakan kegiatan yang berkelanjutan, dimana dalam usulan ini kegiatan hanya dibatasi pada pencatatan transaksi keuangan dengan melakukan pelatihan penggunaan teknologi informasi khususnya Microsoft
Excel untuk melakukan pencatatan transaksi keuangan yang memenuhi standar akuntansi sederhana dan pembuatan website untuk sosialisasi dan penguatan image. Pengelola dan karyawan yang juga merupakan warga sekitar yang menjalankan usaha bengkel ini memiliki antusiasme tinggi terhadap pelaksanaan pengabdian masyarakat ini.

Hasil luaran dari kegiatan pengabdian ini berupa:

1. Keterampilan pencatatan pembukuan keuangan menggunakan PC.

2. Keterampilan pengelolaan website perusahaan.

3. Dokumentasi kegiatan

\section{Evaluasi}

Pelaksanaan kegiatan pengabdian telah berlangsung dengan baik. Meskipun di akhir kegiatan pandemic CoVid-19 mulai dialami di Denpasar, belum berpengaruh terhadap jumlah pelanggan yang datang maupun pendapatan kotor perusahaan.

Suatu rancangan dan pengembangan website telah dihasilkan dan untuk web juga sudah disewakan domain dan hosting dengan url: warasmotor.web.id.

Seiring dengan keadaan pandemi yang belum berakhir, diperlukan peningkatan intensitas pemanfaatan website sebagai media penyampaian informasi dan pemasaran yang cukup efektif untuk meraih calon pelanggan baru.

\section{Manfaat Kegiatan}

Dari pelaksanaan kegiatan ini mitra dapat melakukan pencatatan pembukuan keuangan menggunakan Microsoft Excel dan melakukan pengelolaan website sebagai media informasi dan pemasaran sehingga diharapkan dapat meraih segmen pelanggan baru.

\section{SIMPULAN}

Kesimpulan yang dapat diambil dari pelaksanaan pengabdian masyarakat ini adalah bahwa pelaksanaan pembekalan tentang pentingnya pencatatan pembukuan 
keuangan yang lebih baik, menggunakan personal computer dengan software Microsoft Excel telah berjalan dengan baik, dan pelatihan tentang pengelolaan back office website telah berjalan dengan baik pula.

\section{UCAPAN TERIMA KASIH}

Puji syukur atas terselesaikannya artikel pengabdian masyarakat ini. Tiada gading yang tak retak demikian juga dengan artikel ini. Pada kesempatan ini izinkan saya menyampaikan terimakasih kepada :

1. Dr. Dadang Hermawan, selaku Rektor Institut Teknik dan Bisnis STIKOM Bali, yang telah memberikan motivasi dan semangat kepada kami.

2. Dr. Evi Triandini, M.Eng., selaku Ketua LPPM ITB STIKOM Bali, yang telah memberikan pengarahan dan motivasi.

3. Bapak Waras Taarufi selaku pemilik dan pengelola bengkel WARAS Motor, yang telah memberikan kesediaannya untuk menjadi mitra dalam pengabdian ini.

4. Redaksi jurnal Widyabhakti yang telah memberikan saran dan masukan demi penyempurnaan artikel ini

\section{DAFTAR PUSTAKA}

Madcoms. 2015. Merancang dan mengelola website. Penerbit : Andi. Yogyakarta : p:6

Yuli Yana. 2018. 40 Manfaat Internet Dalam Berbagai Bidang, https:// manfaat.co.id/40-manfaat-internet-da lam-berbagai-bidang,13 Mei 2019.

Munawir Nasir, Jafar Basalamah, Aditya Halim Perdana Kusumah. 2019. Kegiatan E-Marketing sebagai bentuk Kewirausahaan Dini Bagi Pelajar, Celebes Abdimas: Jurnal Pengabdian Kepada Masyarakat, http://journal.lldikti9.id/

CER/indexVol 1, No. 1, April 2019. Pp: 01-08

Nugroho Anggun, Bagiarta Nyoman, Santoso Joko. 2020. PKM Pembuatan Logo dan Pelatihan Pemasaran Berbasis Social Media pada Pabrik Roti "HM" Karangasem. WidyaBhakti: Jurnal Ilmiah Populer. Vol 2 No. 22020. 117-122.

Tim PusDikLat Kemenkeu. 2018. Pembuatan Fungsi Excel Sendiri (VBA Macro). Materi DikLat VBA Macro. https://klc.kemenkeu .go.id/course/diklat-microsoft-exceltingkat-tinggi/curriculum/ Diakses terakhir 12 Maret 2020. 